\title{
COMMITTEE ON GLASS-WORKERS' CATARACT
}

The following is taken from the Report of the Chief Inspector of Factories for 1921.

Constitution.-The Glass-workers' Cataract Committee of the Royal Society was appointed on June 18, 1908. The members were Sir William Abney, Sir Clifford Allbutt, Dr. H. K. Anderson, Sir John Rose Bradford, Dr. G. J. Burch, Sir William Crookes, Mr. Marcus Gunn, Mr. E. Nettleship, Mr. J. Herbert Parsons, and Dr. A. D. Waller. Since its appointment the Committee has lost by death Dr. Burch, Sir William Crookes, Mr. Marcus Gunn and Mr. Nettleship.

Reference.-The Committee was appointed to investigate "the physical and physiological problems" involved in the causation of Glass-Workers' Cataract, and to advise as to the measures which should be adopted for the prevention of the disease. (See letter from Home Office, April 7, 1908.)

Preliminary Investigation.-In August and September, 1908, a visiting Sub-Committee, consisting of Messrs. Anderson, Burch, Gunn and Parsons, visited glass works at Sunderland, Gateshead, and St. Helen's. They acquainted themselves with the incidence and clinical manifestations of the disease, and with the conditions in which the men carry out their work. In March, 1909, Sir William Crookes visited the Glass Bottle Works of Messrs. Nuttall \& Co., at St. Helen's, and made accurate investigations of the temperature of the molten glass in the tanks and of the radiations emitted. A series of spectro-photographs was taken.

A suitable spectroscope enables the observer to analyse the radiations emitted from such a source of energy as molten glass. By its means the luminous rays are spread out into a spectrum, which is red at one end and violet at the other. The wave-lengths of the radiations are greatest at the red end and diminish continuously to the violet end. Beyond each end of the luminous spectrum are radiations which are invisible to the human eye. Those of shorter wave-length beyond the violet end-the ultra-violet rays-are extremely active in producing chemical change, e.g., on a photographic plate, and are, hence, known as the chemical or actinic rays. The radiations of longer wave-length beyond the red end are specially active in raising the temperature of bodies on which they fall and by which they are absorbed. They are, therefore, known as the heat rays. A source such as molten'glass might also conceivably emit X-rays.

The preliminary investigation showed :-

(1) That no X-rays were emitted.

(2) That luminous and ultra-violet rays were emitted in considerable amount. 
(3) That the preponderant emission was of heat rays.

It is an established principle that radiations do not produce any change in the physical or chemical constitution of any substance upon which they fall unless they are absorbed by the substance. Hence the next step in the investigation was to discover which, if any, of the radiations were absorbed by the media of the eye.

Luminous Rays. - The luminous rays are not absorbed by the transparent media of the eye to any appreciable extent, and consequently cannot be the cause of cataractous changes in the crystalline lens.

Ultra-violet Rays.--It is known that ultra-violet rays are absorbed by various structures of the body. They are the cause of inflammation of the eye known as Snow Blindness and Electric Light Ophthalmia. Experiments were therefore carried out by Messrs. E. E. Henderson and Parsons, and were continued and completed by Mr. E. K. Martin to determine the effects of exposure of rabbits' eyes to light rich in ultra-violet rays and the absorption by the media of the eye of these rays.

The experiments showed :-

(1) That, although the cornea absorbs some of the shorter ultra-violet rays falling upon the eye, there are others of longer wave-length which pass through the cornea unimpeded, but are absorbed by the crystalline lens. It is therefore possible that ultra-violet rays may be the cause of changes in the lens substance, and that these may be of such a nature as to produce opacities, i.e., cataract.

(2) That definite changes in the lens are, in fact, caused by repeated and prolonged exposure to ultra-violet radiation. They occur chiefly in the anterior portion of the lens, but no changes of the type of Glass-Workers' Cataract have hitherto been obtained by experimental methods.

Heat Rays. - The absorption of radiant heat by the media of the eye was investigated for the Committee by Messrs. H. Hartridge and A. V. Hill. The research involved the design and construction of an infra-red spectrometer, and led to results of great value. Of these the most important from the point of view of the origin of Glass-Workers' Cataract are :-

(1) That a considerable percentage of the heat energy incident on the cornea is absorbed by the crystalline lens. It is therefore possible that cataract may be induced in this manner. In this connection it is worthy of note that sporadic cases of cataract, similar to those found in Glass-Workers, have been observed in Iron-Workers. The fewness of the recorded cases may be due to the shorter duration of direct exposure of the eyes to the radiation.

(2) That the iris absorbs practically all the heat radiation 
which falls upon it. The importance of this observation will now be discussed.

Indirect Action.-The crystalline lens receives its nourishment from fluid which is derived from the vascular coat of the eye, especially the ciliary body, which is continuous with the iris. If, owing to disease or disturbance of function of the ciliary body this fluid is altered in character, the lens is likely to suffer. The deleterious effect usually manifests itself in the form of cataract commencing in the posterior layers of the lens and therefore somewhat resembling Glass-Workers' Cataract. Since GlassWorkers' Cataract does not usually arise until after many years' exposure to the conditions of work, it has seemed probable to some members of the Committee that it is not due to direct action of the radiation upon the lens itself, but rather to indirect action affecting the nutrition of the lens through the ciliary body. Certain preliminary experiments carried out by Messrs. E. E. Henderson and Parsons, and by Mr. E. K. Martin afford some support to this hypothesis. The observation of Messrs. Hartridge and Hill on the absorption of radiant heat by the iris points strongly in the same direction.

Prevention.-Although the exact nature of the radiation $\overrightarrow{0}$ responsible for the development of Glass-Workers' Cataract, ane $\stackrel{\sim}{\rightarrow}$ the exact rationale of its action were as yet unknown, Sir William Crookes early instituted experiments on behalf of the Committee्er with a view to discovering some means of cutting off as much as possible of the ultra-violet and infra-red radiation from the eye. $\mathrm{He}$ prepared a large number of glasses, containing salts of various metals, and succeeded in discovering several which excellently fulfilled the requirements. Some of those which absorb ultra-violet radiation have since been placed upon the market and are known as "Crookes's glass." It is probable that if the workers wore spectacles made of the appropriate glass the disease would be abolished. It is to be remembered, however, that it is almost impossible to get workmen to wear protective glasses. The attempt has indeed been made with unsatisfactory results.

Summary.-The investigations already carried out show:-

(1) That the luminous rays are not the cause of the disease.

(2) That ultra-violet radiation is not the cause in so far as any direct action upon the lens is concerned.

(3) That the evidence is strongly in favour of the view that heat is the active agent.

(4) That it is uncertain whether the heat radiation acts directly on the substance of the lens, or indirectly by disturbing

the nutrition of the lens.
(5) That possibly ultra-violet radiation may play some part in $\stackrel{0}{\Phi}$
$\stackrel{0}{0}$ the causation by indirect action on the nutrition of the lens. 
Future Work.--It will be seen that very satisfactory results, both as regards cause and prevention, have already been obtained. The research cannot, however, be regarded as completed. Further investigation of the effect of heat radiation upon the eye is needed, especially.with the object of producing cataract experimentally by this means. For this purpose further research on the chemistry of the crystalline lens is required. It is also most desirable that the exact method of action of the radiation, whether direct or indirect, as explained above, should be settled.

Further, the difficulties of manufacturing glasses which absorb the heat radiation have not yet been completely overcome, and it is very important that this work should be carried out.

\section{COUNCIL OF BRITISH OPHTHALMOLOGISTS}

\section{A Report on some Public Authorities who are in the habit of referring Ophthalmic Cases to Hospitals for Examination, Treatment and (or) Report.}

The following Report was passed at the meeting of the Council of British Ophthalmologists on July 5 last :-

The Committee has enquired into the medical service of the following Public Authorities:-

Post Office. Army Pensions. Old Age Pensions for the Blind.

Post Office.-The Committee has ascertained that the Postal Authorities provide medical treatment for those of their employés whose pay is under a certain wage limit, with the object of ensuring their efficiency for the performance of their duties, and that they appoint medical officers for this purpose. The Committee notes that no ophthalmic surgeons or other specialists are officially appointed.

The cases requiring advice, treatment and report (by ophthalmic surgeons) are so numerous that the efficiency of the service cannot be maintained without such assistance; the result is that the medical service of the post office is being supplemented by the services of the honorary staffs of the special ophthalmic hospitals and of the eye departments of the general hospitals.

The Committee recommends that the Council should report to the Postal Authorities that their medical service cannot be adequate unless it includes the service of ophthalmic surgeons whose duty it should be to examine the eyes of recruits, to treat employes, and when necessary, to furnish reports upon which official action can legitimately be taken. 